\title{
Agro-physiological response of potato to "sustainable" deficit irrigation in the plain of Saïs, Morocco
}

\author{
Omnia El Bergui ${ }^{1,2}$, Aziz Abouabdillah ${ }^{1 *}$, Rachid Bouabid ${ }^{1}$, Nabil El Jaouhari ${ }^{1,3}$, Youssef \\ Brouziyne $^{4}$, and Mohamed Bourioug ${ }^{1}$ \\ ${ }^{1}$ Ecole Nationale d'Agriculture de Meknès, Meknès, Morocco \\ ${ }^{2}$ Institut Agronomique et Vétérinaire Hassan II, Rabat, Morocco \\ ${ }^{3}$ Moulay Ismail University, Faculty of Science, Meknes, Morocco \\ ${ }^{4}$ Mohammed VI Polytechnic University, International Water Research Institute - Benguerir, Morocco
}

\begin{abstract}
Morocco is one of the countries who's facing an insufficient water supply for irrigation, therefore it is seeking for new technologies allowing irrigation management evolution. Deficit irrigation is for this reason one of the recommended approaches to deal with this alarming situation. This study deals with the assessment of Sustainable Deficit Irrigationon potatoes production (Var. Desiree). The experiment was conducted on an experimental plot in open field in Morocco. Three water regimes were applied: T1 control (100\%), T2 (75\%) and T3 (50\%) of crop evapotranspiration ETc. This is a complete random block device with four repetitions. Measurements focused on monitoring vegetative, ecophysiological and yield parameters. The results obtained show that: (i)the irrigation regime did not significantly affect the eco-physiological parameters nor the vegetative parameters, except for the height of the plants; (ii) in terms of yield, a deficit of less than $25 \%$ of ETc did not lead to a significant difference compared to the control treatment and reached 41,17 tones/ha compared to the $100 \%$ ETc with $42,51 \mathrm{t} / \mathrm{ha}$; (iii) irrigated treatments at less than $50 \%$ of daily ETc revealed extreme yield loss $(20,96$ Tonnes/ha);(iv) finally, the best agronomic water use efficiency was recorded for irrigated treatments at $75 \%$ of Etc.
\end{abstract}

\section{Introduction}

In a climate change and water scarcity context recognized worldwide, Morocco would be ranked among the 45 countries affected by this situation and is likely to reach an extremely high level of water stress by 2040. This situation is challenging and that will impact the Moroccan population and in particular the agricultural industry [1]. The great challenge for the coming decades will then be to increase food production with less water, and thus to improve water use efficiency.

\footnotetext{
* Corresponding author:aziz.abouabdillah@email.com
} 
Deficit irrigation is one of the most recommended approaches to deal with water scarcity in agriculture. This method is applied by reducing irrigation water inputs without affecting the yield [2]. The crop is exposed to a certain level of water stress either during a given period of time, known as regulated deficit irrigation (RDI), or throughout the entire growing period and is therefore referred to as sustainable deficit irrigation (SDI). Many scientists have observed that the resulting reduction in yield may be insignificant compared to the benefits obtained; notably reduced water consumption.

Potato (solanum tuberosum) is one of the most important and widespread crops in the world. It plays a major role in the international and national food system since it is the main non-cereal foodstuff. It has become cultivated in almost all regions of Morocco, occupying an average area of more than 60,000 ha each year (MAPMDREF). Thus, it holds a crucial place among market garden crops in Morocco and plays a very important economic function. The potato has shallow roots and is sensitive to water stress. However, rainfall is insufficient to sustain its production, making irrigation crucial. According to Gultekin et al [3], potato yields were significantly affected depending on the water deficit and the best yield achieved (47.13 Tonnes/ha) was recorded by the treatment receiving $100 \%$ of the water needs.Hamida et al [4] have reported that the potato's response to water scarcity indicated that deficit irrigation increased potatowater use efficiency.

In order to verify and test these results; this study was carried out in the region of Fez Meknes, North-West Morocco, addressing thesustainable deficit irrigation of potato. The main objective of this experiment is to assess the agro-physiological response of potatoes to continuous deficit irrigation with different levels of water restriction.

\section{Material and method}

\subsection{Experimental site}

The experiment was carried out on an experimental plot of $4000 \mathrm{~m}^{2}(0.4 \mathrm{ha})$ at the National School of Agriculture of Meknes (ENA-Meknès), located in the area of Mejjat-Sidi Slimane Moul El Kifane, Fez-Meknes region, of which the coordinates are 3350'37. 1 "N latitude and $5^{\circ} 28^{\prime} 30.0$ "W longitude. The experimental plot was fallow for more than 4 years before that was planted with onion in 2018 followed by potato in March 2019. The region's weather ranges from Mediterranean to continental with cold winters and hot summers.

The physico-chemical soil analysis carried out in 2019 at the Ferticonseil laboratory of ENA-Meknès, show that the soil texture is loamy-clay with an average of $46 \%$ loam, $37 \%$ clay and $17 \%$ sand. The water content at field capacity $(\mathrm{Fc})$ and permanent wilting point (PWP), estimated by the SPAW software [5]based on the Saxton formula, is $38 \%$ and $22 \%$ respectively.

In order to determine the water amount to be applied for each irrigation, it was necessary to calculate the Readily Available Water(RAW) equivalent to the Net Maximal Amount of irrigation, which corresponds to the amount of water that a soil can hold in the effective root depth, and which is calculated by using the formula below:

$$
R A W=f x(F c-P W P) x R d x P H S_{(1)}
$$

With

f: Irrigation triggering percentage $(5 \%)$.

Fcc: Humidity at field capacity $(38 \%)$

Hpfp: Humidity at permanent wilting point $(22 \%)$ 
Rd: effective root depth

PHS: Percentage of humidified soilcorresponding to the percentage of soil moisture estimated at $65 \%$ for this installed irrigation system.

All the key parameters of the RAW were calculated at the beginning of the experiment. The factor $\mathrm{f}$ is an important indicator for judging the work quality in irrigation management. The value of $f$ chosen for this test is $5 \%$.

The basic meaning of $\mathrm{f}=5 \%$ is that irrigation is triggered when $5 \%$ of the available soil water storage is consumed. The choice of this frequency was based on the study carried out by Lamrahli in 2018 in the same field which compared two values of the f coefficient (5 and $10 \%$ ) for onion crops and showed that a frequency of $5 \%$ gives better results in terms of water absorption and water use efficiency as well as in terms of yield.

\subsection{Experimental Protocol}

The plant material used for this study is potato (Solanum tuberosum) of the 'desirée' variety imported from the Netherlands. Seeding was carried out on March 5, 2019 in the field at a depth of $10 \mathrm{~cm}$, on rows spaced at $80 \mathrm{~cm}$ apart and $30 \mathrm{~cm}$ tuber spacing.

The experimental design adopted is a complete randomized block design (DBAC), with a single source of heterogeneity with four repetitions and three water regimes.

The three water regimes are as follows:

- Control T1 is a comfort irrigation with 100\% crop evapotranspiration ETc throughout the whole cycle;

- Treatment T2 corresponds to sustainable deficit irrigation with an application of $75 \%$ Etc during the whole cycle; (i.e. a $25 \%$ of water restriction).

- Treatment T3: sustainabledeficit irrigation with 50\% ETc applied throughout the cycle; (i.e. $50 \%$ of water restriction).

A localized irrigation was provided by a drip system, including drippers each supplying 1.6 $1 / \mathrm{h}$, spaced at a distance of $0.4 \mathrm{~m}$ from each other.

As this study focused on water supply, the crop was conducted in a non-limiting manner concerning the other factors (tillage, density, fertilization, weeding, etc.).

\subsection{Irrigation water needs calculation}

The determination of the crop water requirement is based on the water balance method. The daily crop evapotranspiration (ETc) is calculated from reference evapotranspiration data ET0 provided by the meteorological station available at the same experimental site. The formula used for the calculation of the ET0 is the Penman-Monteith equation [6].

The formula for calculating the net water requirement (NWR) of the potato is as follows:

$$
N W R=E T c=\left(E T 0^{*} K c\right)_{(2)}
$$

The gross daily water requirement applied concerns a percentage of the daily water requirements (DWR) calculated by the crop evapotranspiration formula below:

$$
\mathrm{GWR}=E T c / C u * E i_{(3)}
$$


$\mathrm{Cu}$ : Uniformity of water distribution coefficient measured at the field and estimated to be 0.92

Ei: irrigation system efficiency estimated at 0.9 for this new irrigation system.

The crop coefficient Kc model used in this study, which depends on the phenological stage of the potato crop, is the one published in the official FAO bulletin 56. This crop coefficient varied between 0.45 and 1.45 depending on the phases of the potato cycle.

\subsection{Plant observations and measurements}

Measurements were taken every 15 days during the trial period on 36 randomly selected individuals, taking 3 plants for each elementary plot (12 plots).

\subsubsection{Growth and development parameters}

Plantheight, leaf density and number of stems were regularly monitored during our study as for the development parameters.

\subsubsection{Eco-physiological parameters}

Measurements included chlorophyll index and leaf temperaturemeasures. It should be noted that leaf temperature measurements were taken using an infra-red thermometer.

The leaf temperature depends on the energy it receives and the energy it eliminates.

\subsubsection{Yield Parameters}

At harvest time, the upper part of each plant was cut off. Then the wet weight of each plant was determined. All samples were then placed in an oven at $60^{\circ} \mathrm{C}$ for 48 hours. All yield components (Number of tubers, tuber length and size, tuber weight) were measured per plant and then the marketable tuber yield per hectare.

\subsubsection{Biochemical parameters}

The extraction and determination of proline was carried out according to the method described by Bates [7].

\subsection{Statistical analysis}

The data analysis of the studied parameters as well as the calculation of means and the graph conception were carried out with the help of the Excel spreadsheet.

Statistical analyses were performed using SPSS software (version 20). The data were first tested for normality and variance uniformity in order to evaluate the statistical claims. The data were then analyzed using a one-way analysis of variance (ANOVA) followed by the Student-Newman-Keuls (SNK) multiple comparison test. 


\section{Results and discussion}

\subsection{The impact of water stress on the growth parameters}

The evolution of the number of leaves of potato plants and the average number of stems per plant at the end of the cycle were not affected by the water restriction. Indeed, there was no significant difference between the different irrigation regimes. Our results are in opposition to those from the study conducted in the northern side of Kenya by Kiptoo et al [8]who found that the number of stems per plant was significantly affected by irrigation doses and therefore the highest number of stems/plant was recorded for the treatment receiving $100 \%$ Etc. However, data analysis of plant height showed a significant effect of irrigation amount (fig.1) The average plants height generally varies between 43.91 and $56.12 \mathrm{~cm}$. It should be mentioned that the highest heights are found in treatments that received high irrigation water quantity, namely treatment $\mathrm{T} 1($ dose $=100 \% \mathrm{ETc})$ and $\mathrm{T} 2($ dose $=75 \%)$ with mean values of $55.77 \mathrm{~cm}$ and $53.33 \mathrm{~cm}$ respectively.

It can be noted therefore that the SDI has led to a decrease in the height of the plants. Indeed, a decrease of $6 \%$ and $24 \%$ was observed respectively for T2 and T3 treatments compared to the control treatment. These results are similar to those of Arafa et al[9], who found that plant height increased significantly with increasing levels of irrigation applied during the potato growing season.

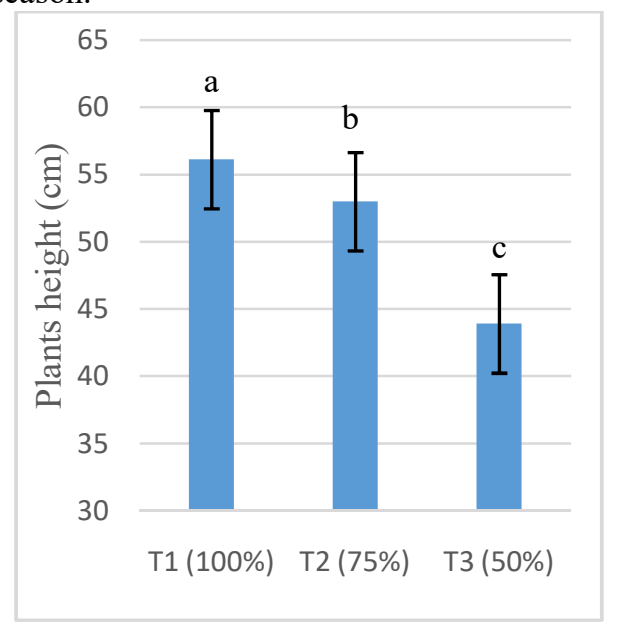

Fig. 1.Average values of potato plant height under different irrigation regimes. The error bars represent the standard deviations

\subsection{The impact of water stress on eco-physiological parameters}

The chlorophyll content of the potato plants was monitored from day 40 after sowing for all treatments.

According to the graph (fig2, A), it can be noted that the highest values were observed in the plants of the T1 $(100 \% \mathrm{ETc})$ and $\mathrm{T} 2(75 \% \mathrm{ETc})$ treatments, and the lowest values were recorded by the plants of the T3 treatments $(50 \% \mathrm{ETc})$. However, analysis of variance did not show a significant effect of theamount of the applied irrigation water on chlorophyll content despite the reduction observed among the three treatments. Thus, the water stress imposed on the plants does not influence their chlorophyll content. 
In the same direction, and according to a study conducted by Zin El-Abedin [10], it was shown that the chlorophyll content values of treatments that underwent water deficiency were similar to the values of the treatments irrigated with $100 \% \mathrm{ETc}$, which is consistent with the results of Yactayo[11] and our results.

On the other hand, Montagu and Woo[12] demonstrated that water deficiency can destroy chlorophyll and prevent its production.

Concerning leaf temperature, the question often arises as to the possible effects on the metabolism during water stress. For a certain decrease in transpiration due to stomatal closure, the increase in leaf temperature would depend strongly on environmental factors [13].

In the current study, leaf temperatures varied with the intensity of water stress applied to the plants for the different treatments. In fact, the highest leaf temperature value is the one measured in the plants of the T3 treatment. However, the lowest temperatures are recorded for treatments that have experienced no or less water stress, i.e. T1 and T2 (fig2, B).

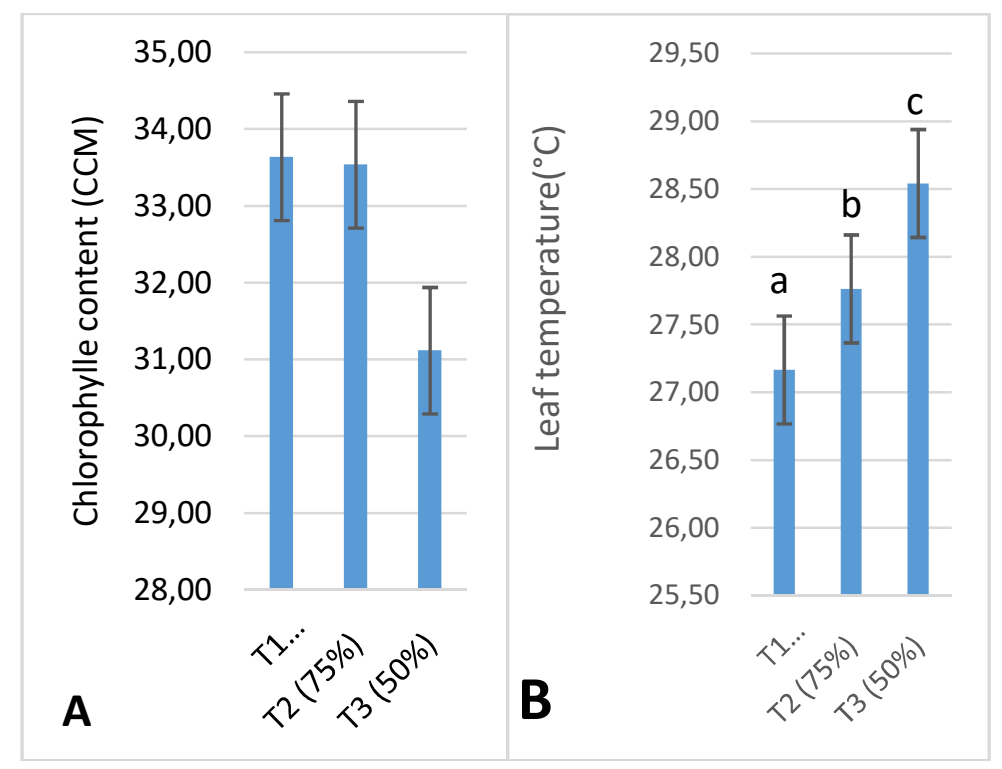

Fig. 2.(A)Values of the relative total chlorophyll content index (TCC) of potato plants in various irrigation regimes. (B): Leaf temperatures ${ }^{\circ} \mathrm{C}$ from different irrigation regimes. The error bars represent the standard deviations.

\subsection{The impact of water stress on biochemical parameters}

Theproline content of the samples issued from different irrigation regimes is shown in figure 3, which also represents the comparison between these treatments. It can be seen from the graphic that the highest proline concentration was found in the most stressed plants, i.e. $50 \%$ of the ETc in T3 treatment, whereas slightly stressed plants $(75 \%$ of the ETc) and non-stressed plants (100\% of the ETc) showed minimum proline levels.

These results are confirmed by the analysis of variance. Indeed, the ANOVA test revealed a significant effect of irrigation dose on proline content. The three treatments are in fact significantly different from one another.

According to Hare [14], free proline will accumulate in various plants in response to a wide range of environmental stresses, so maintaining high water levels prevents the 
accumulation of osmotic adjustments, such as proline and total soluble sugars [15].Delauney[16]added that it is generally accepted that proline plays a cardinal role as an osmoregulatory agent in plants subjected to hyperosmotic stresses, mainly drought and soil salinity. Indeed, the accumulation of this acid can be part of a general adaptation to poor environmental conditions.

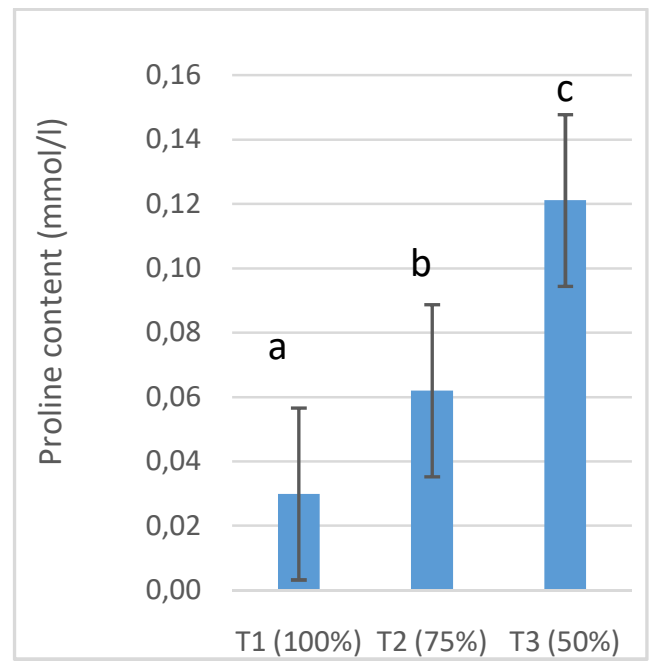

Fig. 3.Different proline concentrations under different irrigation regimes. The same letters indicate values that do not represent a significant difference by the SNK test. The error bars represent the standard deviations

\subsection{The impact of water stress on yield parameters}

Descriptive data analysis of the average tubers number per plant at harvest showed that the lowest number of tubers per plant was 6.83 tubers per plant recorded among the plants of the T3 treatment $($ dose $=50 \%$ ) and the highest number of tubers per plant was 8.75 tubers per plant among the plants of the $\mathrm{T} 1$ treatment (dose $=100 \%$ ). It should be noted that the means of the tubers number are very close despite the water restriction.

Indeed, the analysis of variance showed no significant effect of the irrigation doses on the tubers number per plant (Fig 4. A).

Our results are in harmony with those of Gultekin, who, according to the results of the Tukey test after two years, showed that the number of tubers per plant was not statistically significant at the $1 \%$ significance level. The results obtained in this study were significantly similar to previous studies.

In the same way as the average number of tubers, the average weight of tubers per plant under the different treatments is shown in Figure 4 (B) below. Descriptive analysis of the mean tuber weight data at harvest showed a highly significant effect of irrigation doses on this parameter. In fact, the highest tuber weights were those recorded in the second treatment $($ dose $=75 \% \mathrm{ETc})$ with an average of $1.15 \mathrm{~kg}$ per plant and $\mathrm{T} 1(\mathrm{dose}=100 \%)$ with an average of $1.12 \mathrm{~kg}$ per plant and the lowest weight was the one recorded in the third treatment (dose $=50 \%$ ETc) with an average of $0.62 \mathrm{~kg}$ per plant.

Concerning tuber size, it appears from the graph (Fig. 4 C) that T2 and T1 treatments resulted in the largest sizes, 58.40 and $57.31 \mathrm{~mm}$ respectively. However, the treatment that recorded the lowest potato size was the T3 with a value of $49.96 \mathrm{~cm}$. Analysis of variance 
showed that there is a significant effect of the water dose on the average tuber size at harvest.

The highest marketable tuber yield was recorded by the T1 treatment (dose $=100 \%$ ETc) which is 42.51 Tonnes/ha, and the lowest yield was that recorded by the T3 treatment (dose $=50 \%$ ) which is 20.96 Tonnes $/ \mathrm{ha}$.

Analysis of variance showed a highly significant effect of irrigation rate on final potato yield. Thus, the multi-mean comparisons test SNK carried out using the irrigation dose allowed to determine the statistically different means, namely, group (a) is composed of the treatment T1(100\%), T2 (dose $=75 \%$ ), and group (b) is composed of the last treatment (fig. 4 D).

Treatment T2 (dose $=75 \%)$ gave almost equal yield to control T1 (dose $=100 \%)$, but a $50 \%$ restriction of ETc resulted in a $49 \%$ yield loss.

Indeed, according to Onder[17], water stress 50\% ETc considerably affects potato yield and its parameters. A water deficiency of more than $33 \%$ of irrigation needs cannot be suggested. At the beginning of potato season, when the growing period is too rainy, a $33 \%$ irrigation deficit may be recommended. However, when the season is not too rainy, full irrigation may be advisable.

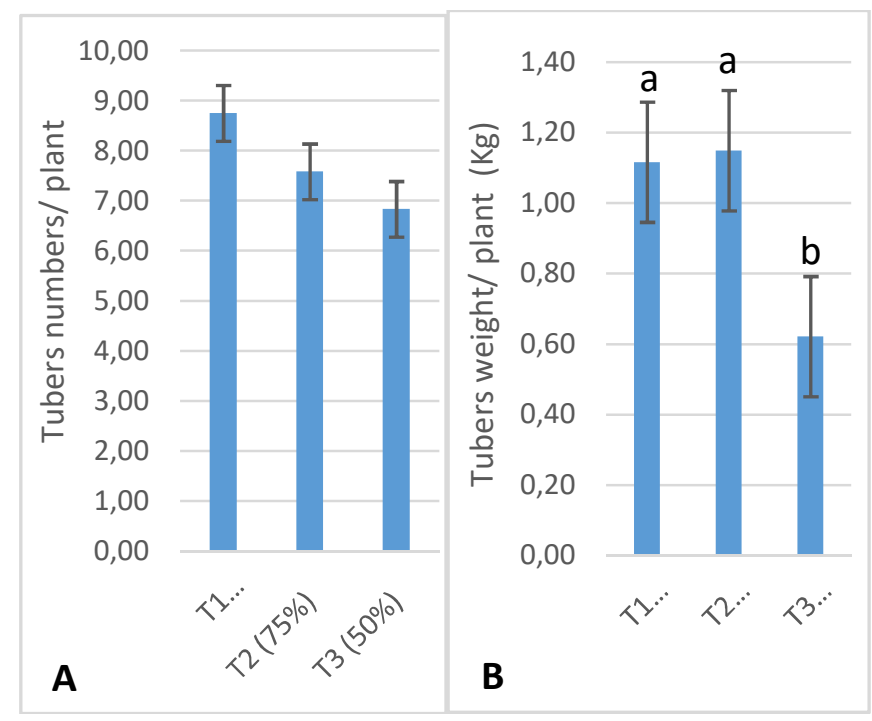




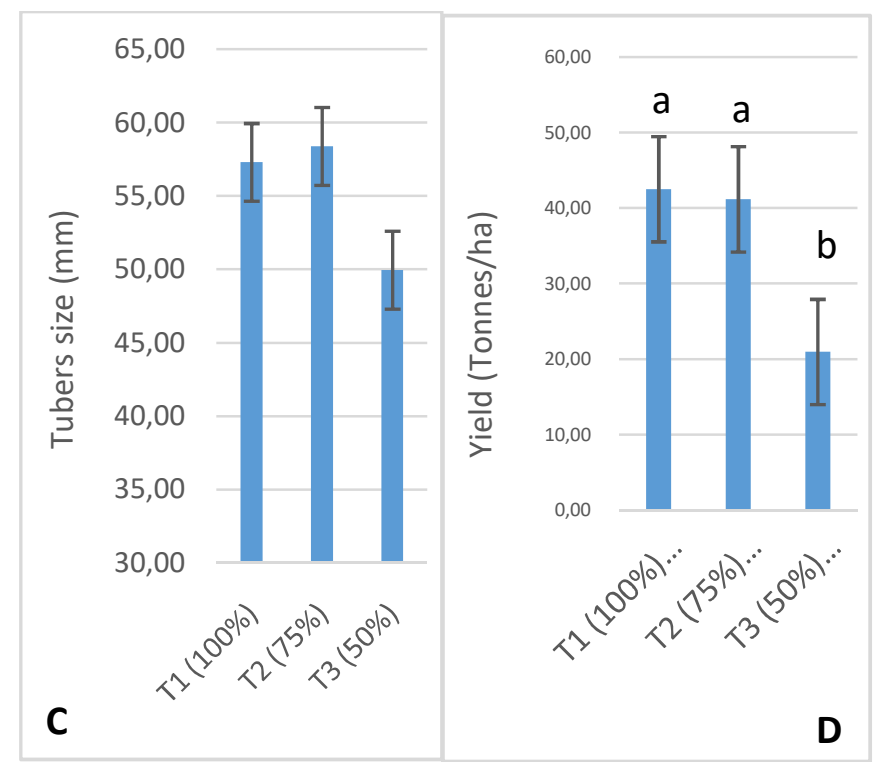

Fig. 4.(A):Different tuber numbers per plant values under different irrigation regimes. (B): Different average tuber weight values per plant under different irrigation regimes. (C): Average tuber size in millimeters at harvest for the different irrigation regimes (D): Estimated yield in Tonnes per hectare for the different irrigation regimes. The same letters indicate values that do not represent a significant difference by the SNK test. The error bars represent the standard deviations.

Finally, the impact of the different irrigation regimes on the agronomic water use efficiency is illustrated in Figure 5, where agronomic efficiency $\left(\mathrm{Kg} / \mathrm{m}^{3}\right)=$ Yield / Water quantity used [18].

According to the graph, the best agronomic water use efficiency was recorded for the $\mathrm{T} 2$ treatment $(75 \%)$. For the T3 treatment, the water savings achieved do not justify the significant yield losses.

\section{Conclusion}

This study assessed the effect of sustainable deficit irrigation with two water regimes $50 \%$ Etc and $75 \%$ Etc on the potato crop. Water restrictions did not affect vegetative parameters, such as the leaves and stem numbers, except for the plant's height, which decreased with increasing water stress. For the eco-physiological parameters; the chlorophyll content did not show a significant difference for all irrigation doses, whereas leaf temperature was affected. Indeed, as water stress increases, the leaf temperature rises as well. The application of $25 \%$ water restriction compared to full irrigation $(100 \% \mathrm{Etc})$ did not affect yield parameters such as weight, size and number of tubers per plant. However, a severe stress with $50 \%$ Etc can result in a considerable yield loss due to a reduction in weight and diameter of the tuber. The best quantitative yields were recorded in treatments T1 $(100 \%$ Etc) and T2 (75\% Etc) with 42.51 Tonnes/ha and 41.17 Tonnes/ha respectively. On the other hand, the plants that underwent extreme stress had a lower yield of 20.96 Tonnes/ha. The effect of applying a water restriction of about $25 \%$ compared to comfort irrigation $(100 \%$ Etc) resulted in water savings of about $77 \mathrm{~mm}$ while maintaining a high yield. In fact, the good water use efficiency was recorded in the plants irrigated at $75 \%$ of the crop water requirements. 
This study demonstrated that, given the region's conditions, it is possible to optimize the use of irrigation water with less impact on yields; this opens up horizons for greater efficiency in agricultural systems, particularly under potential water shortage scenarios.

\section{Acknowledgements}

Thiswork has been carried out under the auspices of the MCRDV research project "COMPETITIVE MECHANISM OF DEVELOPMENT RESEARCH AND VULGARISATION" and we gratefully acknowledge the financial support provided by the Ministry of Agriculture, Fisheries, rural development, water and forest. We are also grateful to the National School of Agriculture of Meknes (ENAM) for their support and cooperation during the project which made this work possible.

\section{References}

1. FAO,Initiative régionale pour faire face à la pénurie d'eau dans la région du Proche Orient et Afrique du Nord Evaluation Nationale Maroc.(2014)

2. M. English, L. James, C. F. Chen. Journal of irrigation and drainage engineering, 116(3), 413-426. (1990).

3. R.Gültekin, A. Ertek. International Journal of Agriculture, Environment and Food Sciences. 2(3) : 93-98. (2018)

4. J. B. Hamida, F. El Mokh, K. Nagaz. Irrigation déficitaire à l'eau salée: étude du cas de la pomme de terre d'automne irriguée au goutte à goutte de surface et souterrain en milieu aride. Numéro Spécial - $\mathrm{n}^{\circ} 35$. (2014).

5. K. E. Saxton, W. J. Rawls. Soil Science Society of America Journal 70, 1569-1578. (2006).

6. R.G. Allen, L.S.Pereira, D. Raes, M. Smith. FAO Irrigation and drainage paper 56. FAO, Rome, 300(9), D05109. (1998).

7. L. Bates, R. Waldren, I. Teare. Plant Soil 39(1): 205-207. (1973)

8. S. Kiptoo, E.C. Kipkorir, et C.K. Kiptum, Revue africaine de l'éducation, des sciences et de la technologie, 4 (4), 65-77. (2018)

9. M. Arafa, M. Darwisch, N. Elhefnawy. J. Plant Production, Mansoura Univ. 6 (11): 1845 - 1860. (2015).

10. T.K.Zin El-Abedin, M.A.Mattar, H.M. Al-Ghobari, A.A.Alazba. Agronomy, 9(4): 172. (2019)

11. W. Yactayo, D. A. Ramírez, R. Gutiérrez, V. Mares, A. Posadas, R. Quiroz. Agricultural Water Management, 123, 65-70. (2013).

12. K.D.Montagu, K.C. Woo.Functional Plant Biology. 26(2):135-145 (1999)

13. T.C.Hsiao. Plant responses to water stress. Annual review of plant physiology. 24(1): 519-570. (1973)

14. P.D. Hare, W.A. Cress. Plant growthregulation, 21(2) : 79-102. (1997)

15. A. Pirzad, M.R Shakiba, S. Zehtab-Salmasi, S.A. Mohammadi, R. Darvishzadeh, A. Samadi. Journal of Medicinal Plants Research. 5(12): 2483-2488. (2011)

16. A.J. Delauney., D.P.S.Verma. The plant journal, 4(2) : 215-223. (1993)

17. S.Onder, M.E.Caliskan., D.Onder, S.Caliskan. Agricultural water management. 73(1): 73-86. (2005)

18. A. Bouaziz, K. Belabbes.Hommes, Terre et Eaux, 32 (124) :4. (2002) 